\title{
Class III PI3K Vps34 Controls Thyroid Hormone Production by Regulating Thyroglobulin lodination, Lysosomal Proteolysis, and Tissue Homeostasis
}

\author{
Giuseppina Grieco, ${ }^{1, *}$ Tongsong Wang, ${ }^{1, *}$ Ophélie Delcorte, ${ }^{1, *}$ Catherine Spourquet, ${ }^{1,{ }^{*}}$ Virginie Janssens, \\ Aurélie Strickaert, ${ }^{2}$ Héloïse P. Gaide Chevronnay, ${ }^{1}$ Xiao-Hui Liao, ${ }^{3}$ Benoît Bilanges, ${ }^{4}$ Samuel Refetoff, ${ }^{3,5}$ \\ Bart Vanhaesebroeck, ${ }^{4}$ Carine Maenhaut, ${ }^{2}$ Pierre J. Courtoy, ${ }^{1, *}$ and Christophe E. Pierreux ${ }^{1, *}$
}

Background: The production of thyroid hormones [triiodothyronine (T3), thyroxine (T4)] depends on the organization of the thyroid in follicles, which are lined by a monolayer of thyrocytes with strict apicobasal polarity. This polarization supports vectorial transport of thyroglobulin $(\mathrm{Tg})$ for storage into, and recapture from, the colloid. It also allows selective addressing of channels, transporters, ion pumps, and enzymes to their appropriate basolateral $\left[\mathrm{Na}^{+} / \mathrm{I}^{-}\right.$ symporter (NIS), SLC26A7, and $\mathrm{Na}^{+} / \mathrm{K}^{+}$-ATPase] or apical membrane domain (anoctamin, SLC26A4, DUOX2, DUOXA2, and thyroperoxidase). How these actors of T3/T4 synthesis reach their final destination remains poorly understood. The PI 3-kinase isoform Vps34/PIK3C3 is now recognized as a main component in the general control of vesicular trafficking and of cell homeostasis through the regulation of endosomal trafficking and autophagy. We recently reported that conditional Vps34 inactivation in proximal tubular cells in the kidney prevents normal addressing of apical membrane proteins and causes abortive macroautophagy.

Methods: Vps34 was inactivated using a Pax8-driven Cre recombinase system. The impact of Vps34 inactivation in thyrocytes was analyzed by histological, immunolocalization, and messenger RNA expression profiling. Thyroid hormone synthesis was assayed by ${ }^{125}$ I injection and plasma analysis.

Results: Vps34 conditional knockout (Vps34 $\left.{ }^{\mathrm{cKO}}\right)$ mice were born at the expected Mendelian ratio and showed normal growth until postnatal day 14 (P14), then stopped growing and died at $\sim 1$ month of age. We therefore analyzed thyroid $\mathrm{Vps} 34^{\mathrm{cKO}}$ at P14. We found that loss of Vps34 in thyrocytes causes (i) disorganization of thyroid parenchyma, with abnormal thyrocyte and follicular shape and reduced $\mathrm{PAS}^{+}$colloidal spaces; (ii) severe noncompensated hypothyroidism with extremely low T4 levels $(0.75 \pm 0.62 \mu \mathrm{g} / \mathrm{dL})$ and huge thyrotropin plasma levels $(19,300 \pm 10,500 \mathrm{mU} / \mathrm{L})$; (iii) impaired ${ }^{125}$ I organification at comparable uptake and frequent occurrence of follicles with luminal Tg but nondetectable T4-bearing Tg; (iv) intense signal in thyrocytes for the lysosomal membrane marker, LAMP-1, as well as Tg and the autophagy marker, p62, indicating defective lysosomal proteolysis; and (v) presence of macrophages in the colloidal space.

Conclusions: We conclude that Vps34 is crucial for thyroid hormonogenesis, at least by controlling epithelial organization, Tg iodination as well as proteolytic T3/T4 excision in lysosomes.

Keywords: Vps34, thyroid, hormone, organification, autophagy

\section{Introduction}

$\mathbf{T}$ HE MAIN FUNCTION of the thyroid gland is to produce the hormones, thyroxine (T4), triiodothyronine (T3), which are essential for the regulation of metabolic processes, and calcitonin $(1,2)$. The production of $\mathrm{T} 3$ and $\mathrm{T} 4$ depends on the correct tissue organization of thyroid epithelial cells, the thyrocytes, into functional and independent units, the follicles. These are composed of a single layer of polarized thyrocytes that form a spherical structure delineating an

\footnotetext{
${ }^{1}$ Cell Biology Unit, de Duve Institute and Université Catholique de Louvain, Brussels, Belgium.

${ }^{2}$ Thyroid Cancer Group, Faculty of Medecine, Institute of Interdisciplinary Research (IRIBHM), Université libre de Bruxelles, Brussels, Belgium.

Departments of ${ }^{3}$ Medicine and ${ }^{5}$ Pediatrics and Genetics, The University of Chicago, Chicago, Illinois.

${ }^{4}$ Cell Signalling, UCL Cancer Institute, University College London, London, United Kingdom.

*These authors contributed equally to this work.
} 
internal space or lumen where the thyrocyte secretory product, thyroglobulin ( $\mathrm{Tg}$ ), is stored in a colloidal form, thus called the colloid lumen. As thyrocytes communicate through gap junctions, each follicle functions as an integrated unit.

Thyroid hormone synthesis depends on apicobasal cell polarity that allows the specific localization of channels, transporters, pumps, and enzymes at the appropriate membrane domains. Iodide from the bloodstream freely traverses the fenestrated endothelium of the thyroid capillaries and is taken up into thyrocytes through the basolaterally localized NIS, thanks to a $\mathrm{Na}^{+}$gradient generated by the $\mathrm{Na}^{+} / \mathrm{K}^{+}$ATPase. An alternative basolateral transporter, SLC26A7, has been recently reported to also control iodide uptake, although its role might be indirect (3). Iodide diffuses freely within thyrocytes and is next transported across the apical membrane into the colloid space through apically localized transporters such as anoctamin or pendrin (SLC26A4).

Iodide is then rapidly oxidized into iodine by thyroperoxidase (TPO) located at the apical membrane, in the presence of hydrogen peroxide $\left(\mathrm{H}_{2} \mathrm{O}_{2}\right)$, generated by the DUOX2/DUOXA2 apical membrane complex. Iodine is incorporated into accessible tyrosine residues, many of them close to the $\mathrm{N}$ - and $\mathrm{C}$-termini of $\mathrm{Tg}$, a large protein secreted by thyrocytes into the colloid space. Iodotyrosine rearranges into hormonogenic peptides, which are the direct T3 and T4 precursors. Thyroid hormone synthesis thus requires basal localization of NIS, SLC26A7, and $\mathrm{Na}^{+} / \mathrm{K}^{+}$-ATPase, apical localization of anoctamin, pendrin, TPO, DUOX2, and DUOXA2, as well as apical delivery of Tg into the colloid lumen and endocytic uptake of iodoTg into thyrocyte lysosomes $(1,2)$.

Specific regulators of thyroid follicular organization have recently been identified (4). Transcriptomic comparison of thyroid FRT cells cultured in two-dimensional monolayers and in three-dimensional (3D) spherical follicles indeed revealed involvement of structural and functional cell elements such as adherens and tight junctions (cadherin-16), cytoskeleton proteins, ion channels, proteins involved in differentiation, and components of the trafficking machinery (e.g., myosin-Vb, Rab17) (4).

There is strong evidence that vesicular trafficking is critical for apicobasal polarization and epithelial function (5-7), but the role of vesicular trafficking in thyroid function is incompletely understood. Vps34/PIK3C3 (also referred to as type III PI 3-kinase) has long been recognized as a main actor involved in the general control of endocytic vesicular trafficking (8-13). Vps34/PIK3C3 also plays an important role in epithelial organization in Drosophila (14) and in autophagy $(12,15)$, both in the initiation of autophagosome formation and in the progression toward autophagosome-lysosome fusion $(16,17)$.

We recently inactivated Vps34 in kidney proximal tubular cells using Wnt4-Cre and Pax8-Cre $(18,19)$. Wnt4-Credriven Vps34 excision caused major perinatal lethality, with abnormalities in kidney cortex development and proximal tubular cell apical differentiation in the surviving mice. With the Pax8-Cre, which triggers recombination in nephrogenic tubules and in nonvascular components of glomeruli 2 days later than Wnt4-Cre $(20,21)$, we observed normal mouse growth until postnatal day 14 (P14) (19). Then, body weight leveled off, and all pups died at $\sim 3$ to 5 weeks of age, probably due to kidney failure. Structural and functional studies of Vps34 conditional knockout ( Vps34 ${ }^{\mathrm{cKO}}$ ) kidneys revealed preserved proximal tubular cell membrane polarity, but impaired apical membrane protein trafficking, thus causing a general proximal tubular cell dysfunction known as renal Fanconi-like syndrome, manifested by polyuria and low-molecular weight proteinuria. $\mathrm{Vps} 34^{\mathrm{cKO}}$ also displayed impaired lysosome size/positioning and blocked autophagy, thereby causing cell vacuolization. We concluded that Vps34 is a crucial component of the trafficking machinery necessary for differentiated proximal tubular cell function and is essential for their overall homeostasis (19). Given that Pax8Cre also triggers recombination in thyrocytes (21), we here investigated the role of Vps34/PIK3C3 in thyroid function and homeostasis.

\section{Materials and Methods}

Mice

$V p s 34^{f l f l}$ mice have been described (22). Pax8-Cre mice were obtained from Bouchard et al. (21). Vps34 ${ }^{f / f l}$ mice were crossed with Pax 8 -Cre; Vps $34^{f / /+}$ mice to generate conditional targeted excision of $V p s 34$ exon 21 in the thyroid of $25 \%$ of offspring $\left(\mathrm{Vps} 34^{\mathrm{cKO}}\right)$. All the other mice $\left(V p s 34^{f / /}, V p s 34^{f / f l}\right.$, and Pax8-Cre; $V p s 34^{f / /+}$ ) were considered as controls as no differences were observed between these groups. Mice were treated according to the NIH Guide for Care and Use of Laboratory Animals, and experiments were approved by the University Animal Welfare Committee, Université Catholique de Louvain (2016/UCL/MD/006 and 2018/UCL/MD/026).

\section{Plasma, tissue collection, and histology}

Blood was collected by eye sinus puncture at sacrifice (P14) under irreversible anesthesia by xylazine $2 \%$ and ketamine $50 \mathrm{mg} / \mathrm{mL}$ ( $200 \mu \mathrm{L} /$ mice i.p.). Thyroid lobes were excised, fixed by immersion in neutral-buffered formaldehyde $\left(4 \%\right.$ F) at $4^{\circ} \mathrm{C}$ under stirring overnight. Samples were paraffin embedded or equilibrated overnight in $20 \%$ sucrose and embedded in Tissue-Tek Optimal Cutting Medium (Sakura Finetek) for cryostat sections.

\section{Thyrotropin and T4 plasma concentrations}

Plasma thyrotropin (TSH) concentrations were measured by a sensitive, heterologous, disequilibrium double-antibody precipitation radioimmunoassay (RIA) as described (23). T4 concentration was measured by coated-tube RIA (Siemens Medical Solution Diagnostics, Los Angeles, CA).

\section{Immunofluorescence}

Immunofluorescence was performed on $5 \mu \mathrm{m}$-thick frozen sections or on $6 \mu \mathrm{m}$-thick paraffin sections (19). Antigen retrieval was promoted in citrate buffer, $\mathrm{pH} 6.0$, at $98^{\circ} \mathrm{C}$ for 20 min using a Lab Vision Pretreatment Module ${ }^{\mathrm{TM}}$ (Thermo Scientific). After permeabilization with phosphate-buffered saline (PBS)/0.3\% Triton $\mathrm{X}-100$ for 5 minutes, nonspecific sites were blocked by 1 -hour incubation in PBS/0.3\% Triton $\mathrm{X}-100$ with $10 \%$ bovine serum albumin (BSA) and $3 \%$ milk, followed by primary antibodies (described in Supplementary Table S1) in blocking buffer at $4^{\circ} \mathrm{C}$ overnight. After extensive washing, sections were incubated with the appropriate AlexaFluor-secondary antibodies in PBS/10\% BSA/0.3\% 
Triton X-100 at room temperature for 1 hour, extensively washed, mounted with Faramount Aqueous Mounting Medium (Dako), and imaged on a spinning disk confocal microscope using a Plan Apochromat $100 \times / 1.4$ Oil DIC objective (Cell Observer Spinning Disk; Zeiss). For whole thyroid section recording, images were acquired using Zeiss Pannoramic P250 slide scanner, stitched and analyzed using Case Viewer software.

\section{Real-time quantitative polymerase chain reaction}

Total RNA was extracted from thyroid lobes using TRIzol Reagent (Thermo Scientific), as described (24). Aliquots of 500 ng RNA were reverse transcribed by M-MLV Reverse Transcriptase (Invitrogen) with random hexamers, as described (25). Primer sequences used are described in Supplementary Table S2. Real-time quantitative polymerase chain reaction (qPCR) was performed as described (25), in the presence of $250 \mathrm{nM}$ of specific primers with Kappa SYBR Fast qPCR Master Mix (Kapa Biosystems) on a CFX96 touch real-time PCR Detection System (Bio-Rad). Data were analyzed using the $\Delta \Delta \mathrm{CT}$ method, using the geometric mean of $\beta$-Actin and Rpl27 as reference genes (26).

\section{${ }^{125}$ I uptake and organification}

At postnatal day 8, mothers and litters were fed with an iodine-free diet for 24 hours. At postnatal day 9 (P9), pups were injected intraperitoneally with $1 \mu \mathrm{Ci}^{125} \mathrm{I}$ (Perkin Elmer) and left for another 24 hours before sacrifice and thyroid dissection. Both lobes were collected in $2 \mathrm{mM}$ methimazole (Sigma) and homogenized with a glass Potter. Total thyroid ${ }^{125}$ I was measured with an automatic gamma counter "Wizard $^{2, "}$ (Perkin Elmer) before protein precipitation using 10\% trichloroacetic acid (TCA; Merck). After a single wash in TCA, radioactivity was measured in the protein pellet. Percentage of protein-bound iodide was calculated using the ratio of precipitated $\mathrm{cpm} /$ total thyroid $\mathrm{cpm}$ (27).

\section{$\mathrm{H}_{2} \mathrm{O}_{2}$-level measurements}

The $\mathrm{H}_{2} \mathrm{O}_{2}$ Assay kit from Abcam (ab102500) was used. At P14, thyroid lobes were collected in ice-cold PBS and homogenized with a glass Potter. Proteins were precipitated with $4 \mathrm{M}$ perchloric acid, and supernatant was neutralized with $3 \mathrm{M} \mathrm{KCl}$ then $1 \mathrm{M} \mathrm{KCl}$ until $\mathrm{pH}$ was comprised between 6.5 and 8.0. Fifty microliters, corresponding to a ninth of a thyroid, was incubated with OxiRed probe and horseradish peroxidase, according to the instructions from the manufacturer. Fluorescence was measured with a GloMax fluorimeter (Promega; Ex/Em = 535/587 nm).

\section{Statistical analyses}

All statistical analyses were performed with Prism software (GraphPad Software, La Jolla, CA). Real-time qPCR values were obtained by the $\Delta \Delta C T$ method and are expressed as boxplots with median, 25th and 75th percentiles, and minmax whiskers. Each graph represents the results from a minimum of eight independent thyroid lobes from at least three different litters. Nonparametric statistical tests were used: Mann-Whitney for single comparisons. Differences were considered statistically significant when $p<0.05(*)$; ** stands for $p<0.01$; *** for $p<0.001$.

\section{Results}

Genetic construction and assessment of Vps34 inactivation

Ubiquitous Vps34 inactivation is embryonically lethal, with embryos dying around embryonic day E8.5 (28). To study tissue-specific roles of Vps34 in vivo, we used a mouse line, which carries a floxed $V p s 34$ allele $\left(V p s 34^{f l}\right)$ that allowed us to conditionally delete the loxP-flanked exon 21 of the Vps34 gene, which encodes a critical sequence of the lipid kinase domain of Vps34 (22). This approach was designed to allow for the expression of a minimally truncated, catalytically inactive Vps34 protein. However, upon conditional expression in megakaryocytes, the level of this truncated Vps34 and its obligatory partner, Vps15, was found to be decreased by 80 $90 \%$ in the megakaryocyte lineage (thrombocytes), indicating instability of the truncated Vps34 protein (22). We thus hereafter refer to the result of this $V p s 34$ truncation as $\mathrm{Vps} 34^{\mathrm{cKO}}$.

We crossed homozygous $\operatorname{Vps} 34^{f / f l}$ mice with $\operatorname{Pax} 8$ Cre; Vps $34^{f l+}$ mice, which is expected to lead to a tissuespecific (thyroid and kidney) conditional excision of exon 21 from both Vps34 alleles in $25 \%$ of the pups, which are further referred to as $\mathrm{Vps} 34^{\mathrm{cKO}}$ mice. $\mathrm{Vps} 34^{\mathrm{cKO}}$ mice were born at the expected Mendelian ratio and showed normal development until P14, then stopped growing and died at $\sim 1$ month of age (19). We therefore analyzed the thyroid of $\mathrm{Vps} 34^{\mathrm{cKO}}$ mice at P14. Of note, eye opening, a marker of cerebral maturation, was usually delayed till postnatal day 10 (P10).

We first assessed the extent of Vps34 excision in the thyroid by quantification of Vps34 messenger RNA (mRNA) using primers that are specific for the total Vps34 or are exon 21-specific. Compared with control littermate pups, we found a $\sim 70 \%$ reduction of exon 21-containing Vps34 mRNA in cKO thyroid extracts. In comparison, we found no significant difference in the abundance of Vps34 mRNA containing exons 22-24 (Fig. 1A). Assuming that Vps34 is equally expressed in all thyroid cell types (expressing and nonexpressing the Cre recombinase), this $\sim 70 \%$ decrease suggests that most thyrocytes in $\mathrm{Vps} 34^{\mathrm{cKO}}$ mice had undergone Cremediated recombination.

\section{Vps34 $34^{\text {KOO }}$ thyroids show signs of hyperstimulation by TSH}

At P14, thyroid glands from Vps34 $4^{\mathrm{cKO}}$ were almost twice as heavy as control glands (Fig. 1B). Histological staining using Periodic-Acid-Schiff (PAS; which in the thyroid reflects production of the $\mathrm{Tg}$ glycoprotein) readily revealed striking differences between thyroid glands of control and $\mathrm{Vps} 34^{\mathrm{cKO}}$ mice (Fig. 1C). Thyroid glands of control mice appeared as assemblies of round follicular sections of variable diameter, filled intensely with colloid and homogenously stained by PAS. Although the histological pattern of $\mathrm{Vps} 34^{\mathrm{cKO}}$ was more variable, three representative individual thyroid sections shown in Figure 1C illustrate irregular follicle shape, especially at the periphery of the gland, and weaker or absent PAS staining (Fig. 1C; Supplementary Fig. S1). In addition, the PASnegative follicular spaces were often filled with nuclei (see Vps34 ${ }^{\mathrm{cKO}}$ no. 3). Quantification revealed that $90 \%$ of control follicles had a regular shape and intense $(+++)$ PAS staining (Supplementary Fig. S1). In contrast, only $50 \%$ of Vps34 ${ }^{\mathrm{cKO}}$ follicles displayed a regular shape, and most of the follicles 

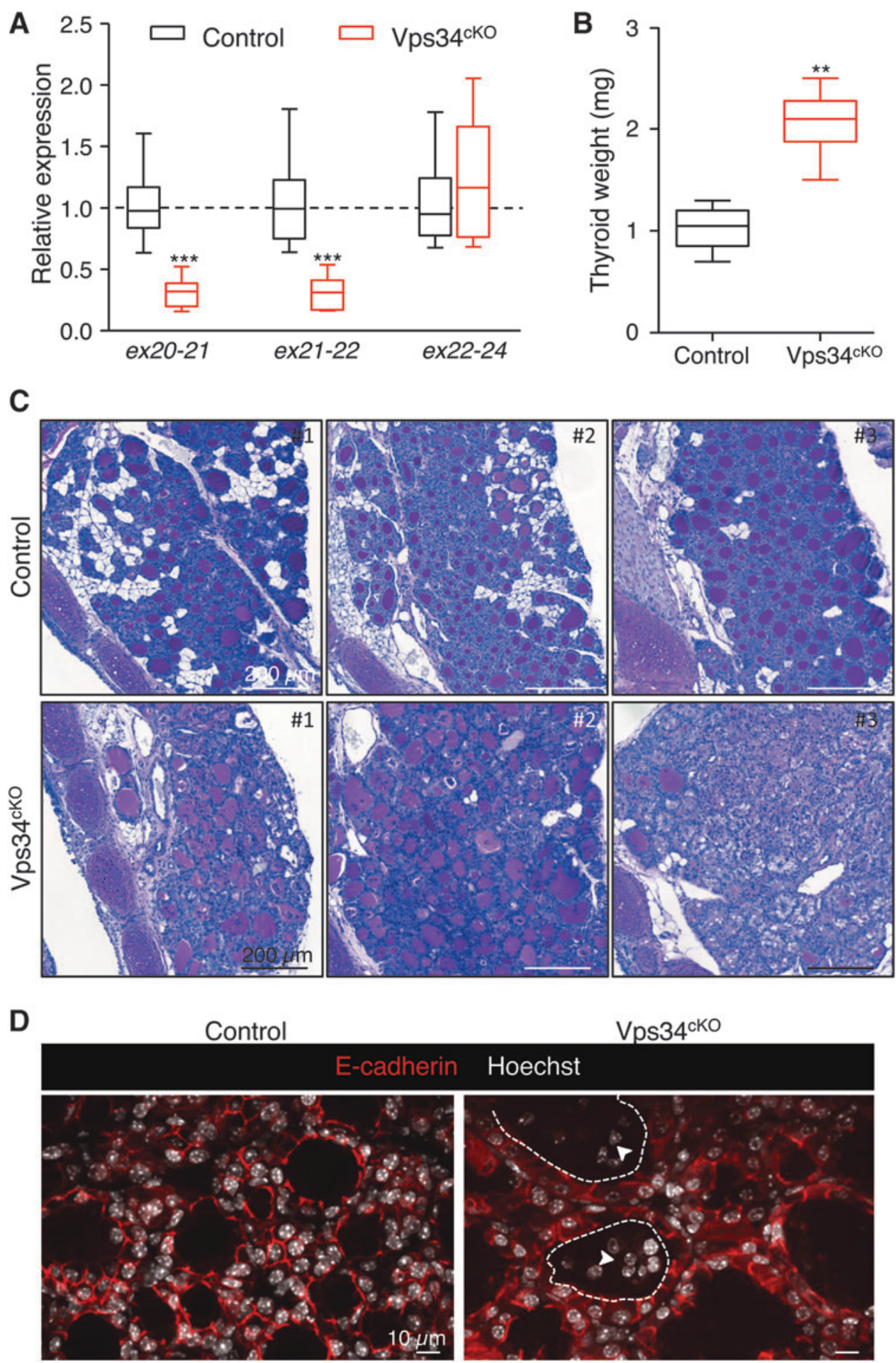

\section{E-cadherin Hoechst}

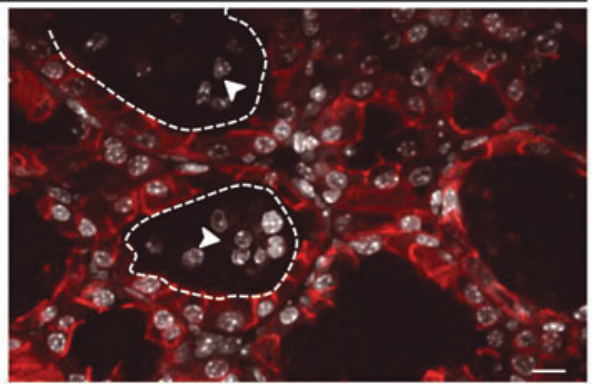

FIG. 1. Genetic and histopathological characterization. (A) Extensive genetic excision of Vps34 exon 21. Compared with control (black boxes), Vps34 ${ }^{\mathrm{cKO}}$ thyroid (red boxes) shows $\sim 70 \%$ reduction in exon 21 mRNA level at P14. The unchanged mRNA level spanning exons 22-24 serves as control. Boxes with median and percentiles of $10 \mathrm{WT}$ and $11 \mathrm{cKO}$ samples; $* * * p<0.0001$ by Mann-Whitney nonparametric test. (B) Increased thyroid weight. Compared with control (black boxes), $\mathrm{Vps} 34^{\mathrm{cKO}}$ thyroid (red boxes) shows a twofold increase in thyroid weight. Boxes with median and percentiles of 8 WT and 6 cKO samples; $* * p<0.01$ by Mann-Whitney nonparametric test. (C) Histopathological evidence for colloid exhaustion. As compared with control thyroid tissues $(n=3)$ where all follicles show regular lumen filling with homogeneous and intense PAS staining, Vps $34^{\mathrm{cKO}}$ thyroids $(n=3)$ present fewer, mostly centrally located, PAS-stained follicles and with weaker staining intensity, and other follicles that appear empty (for further quantification; Supplementary Fig. S1). (D) $\mathrm{Vps} 34^{\mathrm{cKO}}$ thyrocytes are altered and follicles contain abundant nonepithelial cells. Nuclei are labeled by Hoechst (shown in white); thyrocyte basolateral contours are labeled for E-cadherin (red); two lumen boundaries are delineated by broken lines. As compared with control thyroid follicles, $\mathrm{Vps} 34^{\mathrm{cKO}}$ follicular structures are frequently irregular and contain additional cells inside the lumen (arrowheads). These cells are not labeled for E-cadherin. cKO, conditional knockout; mRNA, messenger RNA; PAS, Periodic-Acid-Shiff; WT, wild type. 

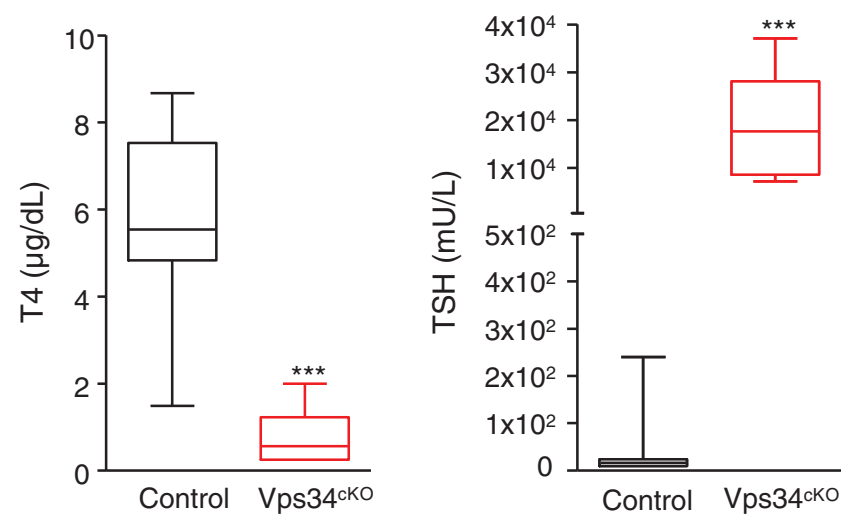

FIG. 2. Vps $34^{\mathrm{cKO}}$ mice display severe hypothyroidism associated with high TSH levels. As compared with control mice (black boxes), T4 plasma level in $\mathrm{Vps} 34^{\mathrm{cKO}}$ is extremely low (red boxes). Conversely, TSH levels are dramatically elevated (10 WT and $9 \mathrm{cKO}$ samples; *** $p=0.0003$ by MannWhitney nonparametric test). T4, thyroxine; TSH, thyrotropin.

were weakly positive for PAS ( + or + ) (Supplementary Fig. S1). In addition, $10-50 \%$ of the $\mathrm{Vps} 34^{\mathrm{cKO}}$ follicles showed no PAS staining (-), and luminal cells were found in $40-70 \%$ of the follicles (Supplementary Fig. S1). Confocal immunofluorescence microscopy for the epithelial marker E-cadherin confirmed heterogeneity of $\mathrm{Vps} 34^{\mathrm{cKO}}$ follicles but also of thyrocytes. Hoechst labeling revealed the presence of several nuclei in a significant fraction of lumina (Fig. 1D). These histological features of follicle remodeling and colloid consumption up to exhaustion suggested perturbed thyroid function.

\section{Vps34 $34^{\text {KOO }}$ causes severe noncompensated hypothyroidism}

To directly test the hypothesis that $\mathrm{Vps} 34^{\mathrm{cKO}}$ could impair thyroid hormone production, plasma was collected at P14 and analyzed for the levels of T4 and TSH. In P14 control pups, values were $6.4 \pm 1.5 \mu \mathrm{g} / \mathrm{dL}$ for $\mathrm{T} 4$ and $75 \pm 110 \mathrm{mU} / \mathrm{L}$ for TSH (Fig. 2). In Vps34 ${ }^{\mathrm{KKO}}$ mice, we found extremely low T4 values $(0.75 \pm 0.62 \mu \mathrm{g} / \mathrm{dL})$ and very high plasma levels of TSH (19,311 $\pm 10,482 \mathrm{mU} / \mathrm{L})$ (Fig. 2). These data indicate severe, noncompensated hypothyroidism. This observation, compatible with the growth retardation observed after postnatal day 15 (19), could be explained by mislocalization of one or several basolateral and/or apical actors involved in thyroid hormone synthesis, as we reported in $\mathrm{Vps} 34^{\mathrm{cKO}}$ kidney proximal tubular cells (19).

\section{Vps34 cKO display reduced iodine organification}

The reduced or absent PAS staining (Fig. 1C) and the low T4 plasma levels in Vps $34^{\mathrm{cKO}}$ mice (Fig. 2) might be caused by defective basolateral iodine uptake, apical transport, and/ or apical organification into Tg. Due to lack or very poor specificity of antibodies directed against murine proteins involved in these processes, we first measured their mRNA expression levels in total thyroids at P14 (Fig. 3). We observed no change in mRNA expression of Nis, Anol, Tg, Tpo, and Duox2, a significant increase in Tshr and Slc26a4 expression, and a significant decrease of Slc26a7 and Duoxa2 mRNA levels. At this stage, we cannot conclude if these changes contribute to the observed hypothyroidism of $\mathrm{Vps} 34^{\mathrm{cKO}}$.

To further test whether basolateral NIS and SLC26A7 and apical ANO1, SLC26A4, TPO, DUOX, and DUOXA were all correctly localized, we functionally assayed their combined activity by injecting iodine-deprived pups at $\mathrm{P} 9$ with

${ }^{125}$ I. At P10, 24-hour postinjection, thyroid lobes were collected and radioactivity measured before and after protein precipitation by TCA (Fig. 4A). ${ }^{125}$ I uptake was not statistically different in $\mathrm{Vps} 34^{\mathrm{cKO}}$ as compared with controls (Fig. 4A), suggesting normal NIS and SLC26A7 function and thus basolateral localization. In marked contrast, only $10 \%$ of thyroid ${ }^{125} \mathrm{I}$ was bound to proteins in $\mathrm{Vps} 34^{\mathrm{cKO}}$ compared

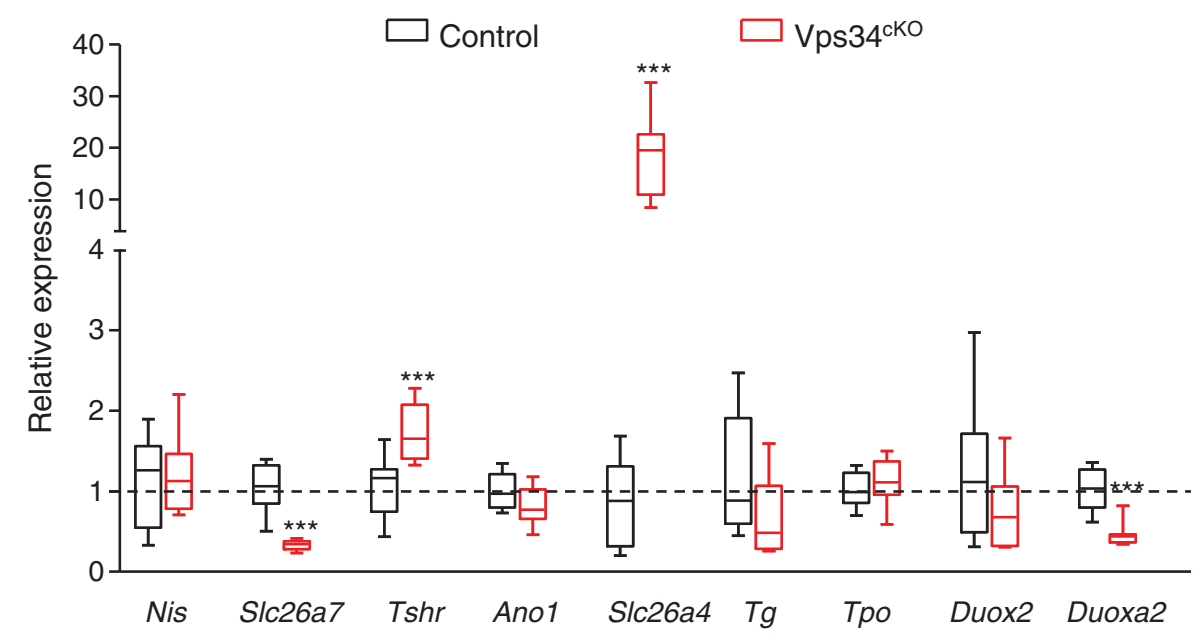

FIG. 3. Relative expression level of main actors of thyroid hormonogenesis at postnatal day 14. Gene expression analysis by real-time qPCR, presented as boxes with median and percentiles. As compared with control thyroid (black boxes), expression in $\mathrm{Vps} 34^{\mathrm{cKO}}$ (red boxes) is preserved for the thyroid-specific genes Nis, Tpo, Tg, and Duox2. Expression of the TSH receptor (Tshr) and of Slc26a4 is significantly increased in Vps34 ${ }^{\mathrm{cKO}}$, while expression of Slc26a7 and Duoxa2 is significantly decreased. Boxes with median and percentiles of $\sim 9$ control and $9 \mathrm{Vps} 34^{\mathrm{cKO}}$ samples; ***p<0.001 by MannWhitney nonparametric test. 

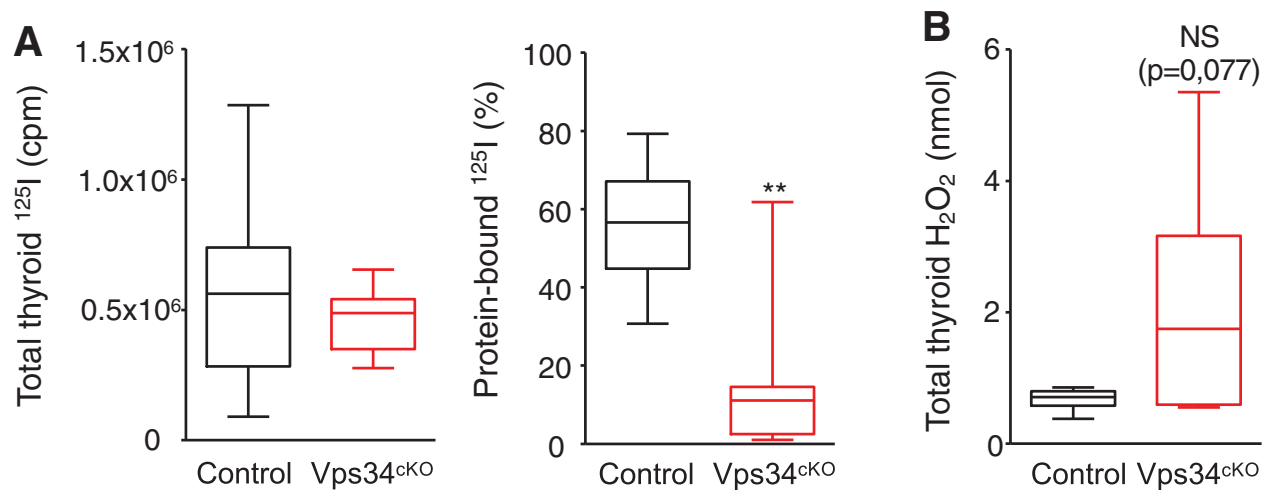

FIG. 4. Normal uptake of iodine but major defect of organification in Vps $34^{\mathrm{cKO}}$ thyroid. (A) Comparable ${ }^{125}$ I-iodine uptake in the thyroid in control genotypes (black box) and $\mathrm{Vps} 34^{\mathrm{CKO}}$ thyroid (red box), but much reduced ${ }^{125}$ I bound to protein (in \%) in $\mathrm{Vps} 34^{\mathrm{cKO}}$ thyroid, suggesting defective organification. Boxes with median and percentiles of 39 (10 Flox/+, 19 Flox/Flox, 10 Cre;Flox/+) and $12 \mathrm{Vps} 34^{\mathrm{cKO}}($ Cre;Flox/Flox) samples; ***p $<0.001$ by Mann-Whitney nonparametric test. (B) Level of $\mathrm{H}_{2} \mathrm{O}_{2}$ in total thyroid extracts shows a trend to an increase in Vps34 ${ }^{\text {cKO }}$ thyroid. Boxes with median and percentiles of 9 control and $9 \mathrm{Vps} 34^{\mathrm{cKO}}$ samples; $p=0.077$ by Mann-Whitney nonparametric test. $\mathrm{H}_{2} \mathrm{O}_{2}$, hydrogen peroxide; NS, non significant.

with $\sim 55 \%$ in controls at this stage (Fig. 4A). This indicates a major effect of Vps34 on one or several apical proteins involved in iodine organification.

Normal Anol and increased Slc26a4/Pendrin mRNA levels suggested correct, or even increased, transfer of iodine in the follicular lumen. On the contrary, decreased Duoxa 2 might impact $\mathrm{H}_{2} \mathrm{O}_{2}$ production. We thus measured the production of $\mathrm{H}_{2} \mathrm{O}_{2}$ in control and $\mathrm{Vps} 34^{\mathrm{cKO}}$ thyroid lobes. Surprisingly, the median level of $\mathrm{H}_{2} \mathrm{O}_{2}$ production in $\mathrm{Vps} 34^{\mathrm{cKO}}$ was higher, even if we observed variability (Fig. 4B), indicating that the DUOX/DUOXA pair is functional in $\mathrm{Vps} 34^{\mathrm{cKO}}$ thyroid tissue. Altogether, these results suggest defective localization of one or several apical actors involved in iodine organification.

\section{Apical polarity is impaired in Vps34 $34^{c K O}$}

Apicobasal polarity is essential for thyrocyte function, and defects in polarity might impact the delivery, and thus localization, of actors involved in thyroid hormone synthesis. As general markers to assess polarity, we used the basement membrane protein laminin, the basolateral $\mathrm{Na}^{+} /$ $\mathrm{K}^{+}$-ATPase, E-cadherin and $\beta$-catenin, the apically localized ezrin (as representative of ezrin, radixin, moesin family), and the tight junction-associated protein ZO-1. Control thyrocytes displayed a well-defined apicobasal polarity with laminin assembled on the basal side, with $\mathrm{Na}^{+}$/ $\mathrm{K}^{+}$-ATPase, E-cadherin, and $\beta$-catenin restricted to the basolateral membrane and separated from apical ezrin by the tight junction, visualized by ZO-1 (Fig. $5 \mathrm{~A}, \mathrm{~B}$ ). In Vps $34^{\mathrm{cKO}}$ thyrocytes, basal laminin was correctly assembled and $\mathrm{Na}^{+} /$ $\mathrm{K}^{+}$-ATPase, E-cadherin, and $\beta$-catenin were restricted to the basolateral membrane, indicating the presence of functional tight junctions. However, on the apical side of $\mathrm{Vps} 34^{\mathrm{cKO}}$ thyrocytes, the ezrin signal was weaker or absent from the lumen-facing pole of some thyrocytes (Fig. 5A), and most cells also lacked ZO-1 protein labeling (Fig. 5B). These data suggest impaired apical polarity in $\mathrm{Vps} 34^{\mathrm{cKO}}$, which might contribute to defective localization of apical actors involved in iodine organification.

\section{Vps34 ${ }^{c K O}$ mice display defective $\mathrm{Tg}$ iodination}

To further analyze the significance of the lack of PAS staining in a fraction of $\mathrm{Vps} 34^{\mathrm{cKO}}$ follicles (Fig. 1C) and the defect in iodine organification (Fig. 4), we assessed Tg protein expression and its associated T4 hormonogenic peptide (iodinated thyroglobulin or I-Tg) by immunofluorescence. Low magnification of control sections showed an identical distribution pattern of $\mathrm{Tg}$ and $\mathrm{I}-\mathrm{Tg}$, homogeneously filling all round colloidal spaces (Fig. 6A). In $\mathrm{Vps} 34^{\mathrm{cKO}}$, the $\mathrm{Tg}$ labeling was more heterogeneous, mainly due to the presence of cells in the colloid. Remarkably, antibodies recognizing the T4 hormonogenic peptide often failed to label colloidal spaces even when containing $\mathrm{Tg}$ in the adjacent section (Fig. 6A), thereby confirming the organification defect (Fig. 4A). Quantifications of 5 control thyroids revealed that $96 \%$ of the follicles are positive for I-Tg (2712 follicles counted; Supplementary Fig. S2). In contrast, only a quarter $(25.2 \pm 11.9 \%)$ of $\mathrm{Vps} 34^{\mathrm{cKO}}$ follicles were positive for the T4-containing hormonogenic peptide (3436 follicles counted in 7 independent thyroids; Supplementary Fig. S2). Of specific interest, whereas the $\mathrm{Tg}$ signal was restricted to the follicle lumen in control thyroid tissue, high magnification revealed that the $\mathrm{Tg}$ signal was frequently seen within Vps34 ${ }^{\mathrm{cKO}}$ thyrocytes (Fig. 6B, arrowheads). These observations indicate that $\mathrm{Vps} 34$ deletion is associated with defective $\mathrm{Tg}$ iodination, as well as reduced $\mathrm{Tg}$ exocytosis and/or excessive $\mathrm{Tg}$ endocytosis.

\section{Impaired lysosomal function and I-Tg proteolysis in Vps34 ${ }^{\text {cKO }}$ thyroid}

Vps34 is involved in endocytic trafficking, and cKO of Vps34 in postnatal kidney glomeruli podocytes causes a strong increase of the overall immunofluorescence signal for the lysosomal membrane marker LAMP-1, indicating enhanced lysosome biogenesis $(29,30)$. We further reported that absence of Vps34 in kidney proximal tubular cells causes an increase in the actual size of lysosomes that were sometimes enlarged and mislocalized toward the basal pole of the cell (19). Given that lysosomal proteases in thyrocytes are 
important to excise hormonogenic peptides to release free T3 and T4, we investigated LAMP-1-labeled structures in $\mathrm{Vps} 34^{\mathrm{cKO}}$ thyrocytes as a proxy for lysosomal function, and its colocalization with $\mathrm{Tg}$ and I-Tg to demonstrate endocytosis. In our conditions, immunofluorescence on control thyroid sections only produced a weak LAMP-1 signal in the E-cadherin-positive epithelial thyrocytes (Fig. 7A, B). On the contrary, a strong and widespread LAMP-1 signal was observed in all Vps34 $4^{\mathrm{cKO}}$ thyrocytes. As shown in the enlarged

\section{A} Control Vps34 $4^{\text {cKO }}$

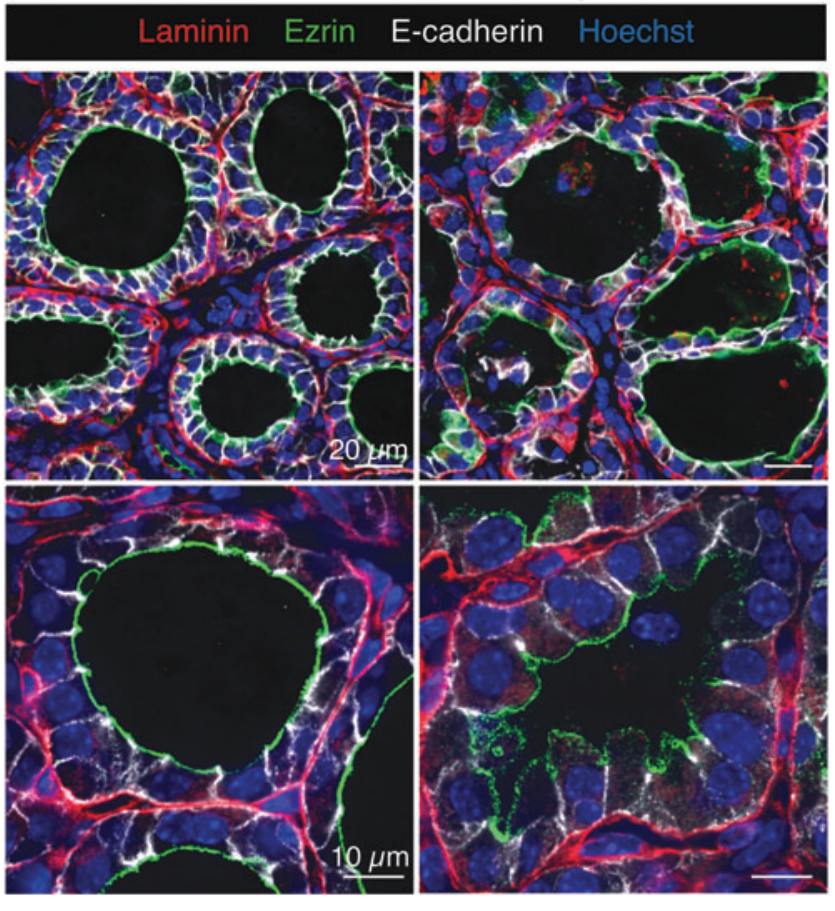

B Control Vps34cko

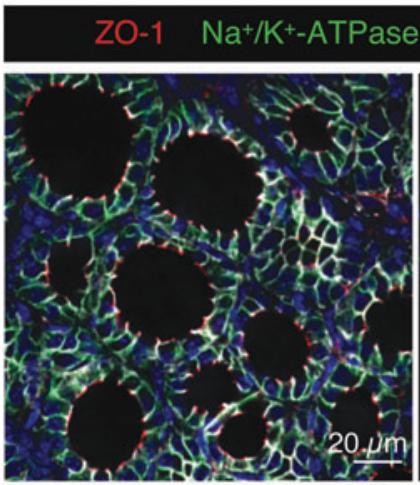

\section{$\beta$-catenin}
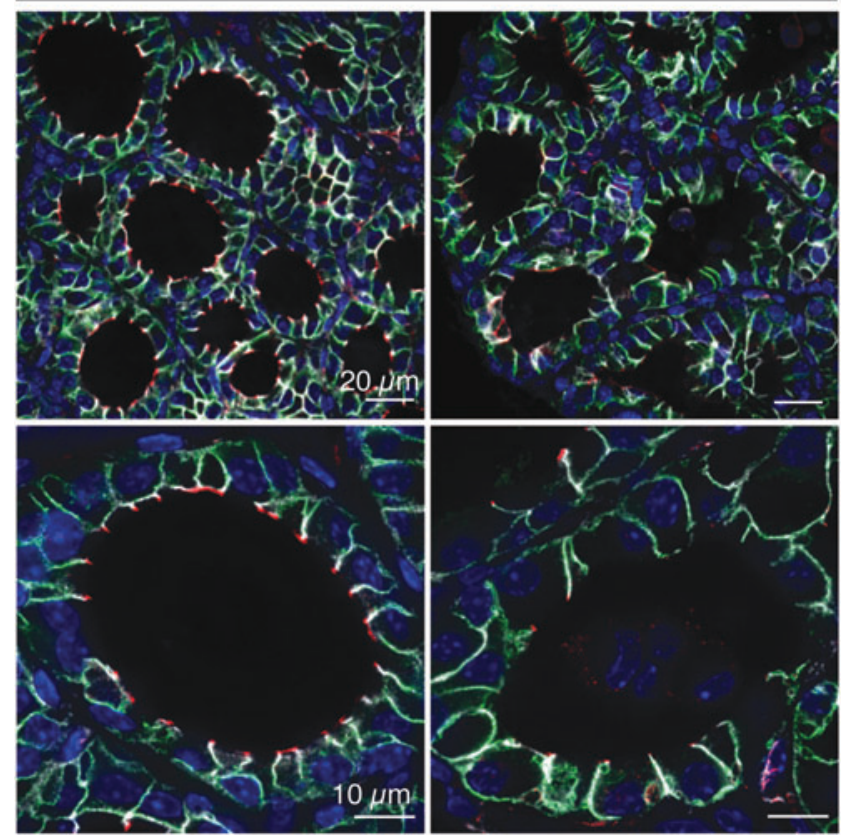

boxes of Figure 7A and B (separate emission channels in white), LAMP-1-positive late endosomes/lysosomes were more abundant, and sometimes enlarged in $\mathrm{Vps} 34^{\mathrm{cKO}}$ thyrocytes as compared with controls. In addition, the intracellular $\mathrm{Tg}$ protein, found in most $\mathrm{Vps} 34^{\mathrm{cKO}}$ thyrocytes (Fig. 7A, arrowheads), most often colocalized with LAMP-1positive structures. This indicates that colloidal $\mathrm{Tg}$ was endocytosed by thyrocytes, but that trafficking to or $\mathrm{Tg}$ proteolysis within the lysosomes was slower or impaired, as compared with controls. Of note, luminal cells also contained LAMP-1 structures positive for Tg (Fig. 7A, right).

Additional supporting evidence for impaired lysosomal proteolysis is based on the analysis of I-Tg (Fig. 7B). Indeed, $\mathrm{Vps} 34^{\mathrm{cKO}}$ thyrocytes often contain intracellular signal for I-Tg, colocalizing within LAMP-1 structures (Fig. 7B, enlarged boxes). Thus, in addition to reduced iodine organification, defective lysosomal excision of T3/T4, if/when hormonogenic peptides were still formed on $\mathrm{Tg}$, is potentially contributing to the low T3/T4 plasma levels observed in $\mathrm{Vps} 34^{\mathrm{cKO}}$ mice (Fig. 2).

\section{Evaluation of autophagy in Vps34 $4^{\text {cKO }}$ thyroid}

The deletion of Vps34 in the kidney also causes a block of autophagy (19). We therefore assessed the expression of p62 (also called sequestosome-1 or SQSTM1), a polyubiquitinbinding protein that interacts with LC3b (microtubuleassociated protein 1 light chain) on the autophagosome membrane and is normally continuously degraded by the autophagy process (31). Since p62 accumulates when completion of autophagy is inhibited, p62 can be used as a marker to study autophagic flux (32). Although we found a weak punctiform LC3 signal in control thyrocytes, we observed no p62 signal, indicating normal autophagic flux in control thyroid tissue (Fig. 8A). As reported, few LAMP-1-labeled structures were found in control thyroids. In contrast, much larger structures, mostly double-labeled for p62 and LC3, were easily detected in the cytoplasm of $\mathrm{Vps} 34^{\mathrm{cKO}}$ thyrocytes (Fig. 8A). As the LAMP-1 signal was increased in $\mathrm{Vps} 34^{\mathrm{cKO}}$, these p62/LC3-positive punctae sometimes colocalized with LAMP-1. We conclude that LC3 could be recruited on p62 aggregates but that progression to autophagosome maturation

FIG. 5. Normal basolateral but impaired apical organization of thyrocytes. (A) Thyroid sections from control (left) and $\mathrm{Vps} 34^{\mathrm{cKO}}$ (right) labeled for laminin (red), ezrin (green), and E-cadherin (white). Nuclei are labeled by Hoechst (shown in blue). In control thyroid, laminin surrounds follicles composed of thyrocytes delineated by basolateral E-cadherin and apical ezrin. In Vps $34^{\mathrm{cKO}}$, laminin normally surrounds follicles composed of thyrocytes with well-defined basolateral E-cadherin but weaker and less regular apical ezrin. Note here apical membrane bulging in the colloidal space. (B) Thyroid sections from control (left) and $\mathrm{Vps} 34^{\mathrm{cKO}}$ (right) labeled for $\mathrm{ZO}-1$ (red), $\mathrm{Na}^{+} / \mathrm{K}^{+}$ATPase (green), or $\beta$-catenin (white). Nuclei are labeled by Hoechst (shown in blue). In control and Vps $34^{\mathrm{cKO}}$ thyroid, $\mathrm{Na}^{+} / \mathrm{K}^{+}$-ATPase and $\beta$-catenin are correctly localized and restricted to the basolateral pole of the thyrocytes, indicating the presence of a tight junction. However, the tight junctionassociated protein $\mathrm{ZO}-1$ is only detected at few apico/ basolateral junctions. 
A

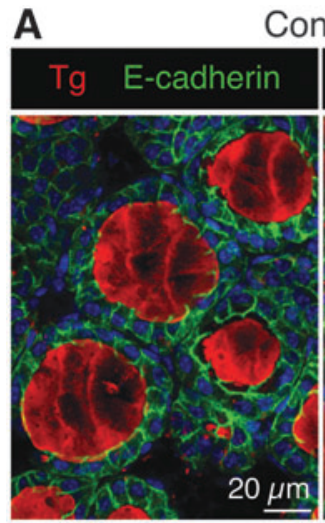

B Control

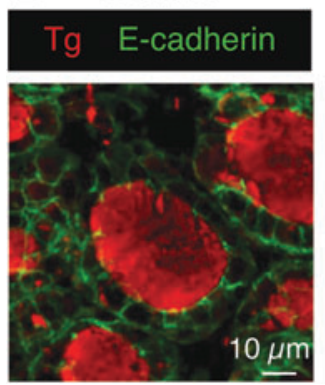

Control
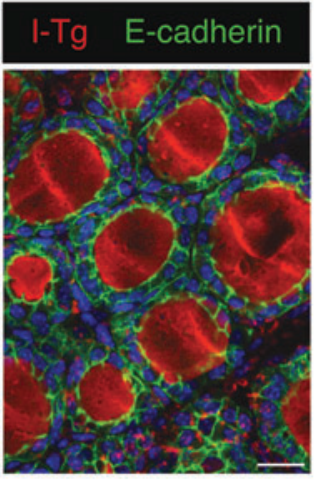

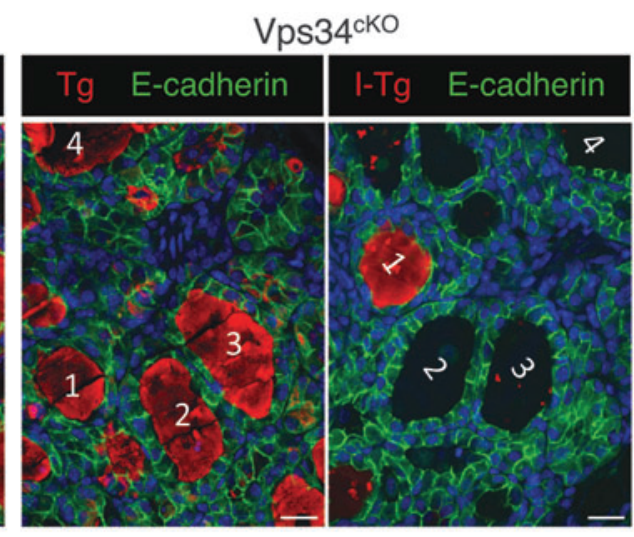

Vps34 ${ }^{\mathrm{ckO}}$

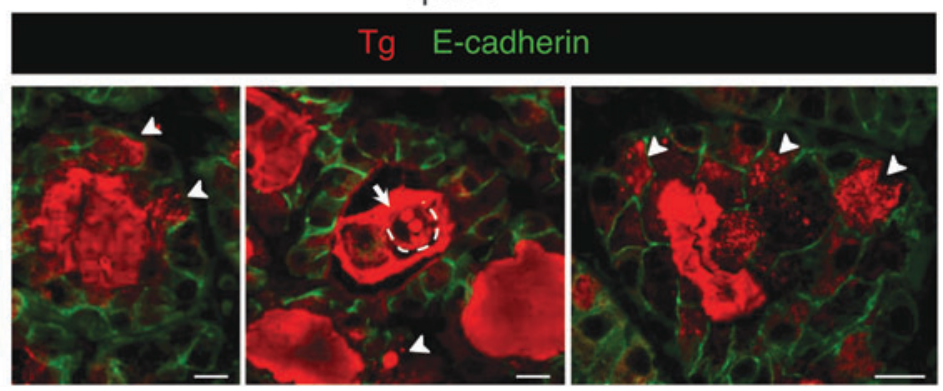

FIG. 6. Evidence for defective iodide organification in $\mathrm{Vps} 34^{\mathrm{cKO}}$ thyroid: follicular lumina with $\mathrm{Tg}$ but devoid of I-Tg. (A) Thyroid sections from control (left) and $\mathrm{Vps} 34^{\mathrm{cKO}}$ (right) labeled for E-cadherin (green) and Tg (red), recognized either for a core protein epitope (Tg), or a hormonogenic peptide (I-Tg). Control follicular lumina are round and uniformly labeled for both $\mathrm{Tg}$ and $\mathrm{I}-\mathrm{Tg}$. In $\mathrm{Vps} 34^{\mathrm{cKO}}$, follicular structures are less regular, with the majority containing $\mathrm{Tg}$, but not the hormonogenic peptide. In Vps34 ${ }^{\mathrm{cKO}}$, two serial (tilted) sections are shown. (B) Comparison of Tg labeling in control and $\mathrm{Vps} 34^{\mathrm{cK} 8}$ thyrocytes. In control follicles, Tg is essentially restricted to lumen, with little or no signal inside thyrocytes. In $\mathrm{Vps} 34^{\mathrm{cKO}}, \mathrm{Tg}$ is readily detected within thyrocytes as collections of submicrometric dots or larger spheres (arrowheads). Of note, some luminal cells (broken line in middle panel) also contain Tg-labeled spheres, indicating active endocytosis (arrow). I-Tg, iodinated thyroglobulin; Tg, thyroglobulin.

and fusion with, and degradation by, lysosomes is arrested. This suggests that deletion of Vps34 in thyrocytes abrogates the autophagic flux.

Recent evidence has demonstrated that p62 is also an activator of the antioxidant KEAP1/NRF2 pathway, which impacts thyrocyte physiology and Tg biology (33). We thus examined the possibility that stabilized p62 would compete with NRF2 for KEAP1 binding in $\mathrm{Vps} 34^{\mathrm{cKO}}$, thus allowing NRF2 to reach the nucleus and activate gene expression. We quantified the mRNA levels of $N r f 2$ and its target genes Nqo1, Gpx2, and Txnrd1. Although we measured a slight decrease of $\mathrm{Nrf} 2 \mathrm{mRNA}$ in $\mathrm{Vps} 34^{\mathrm{cKO}}$, two of its target genes, namely the quinone reductase, Nqol, and the thioredoxin reductase 1, Txnrd1, were upregulated 1.9- and 3.5-fold, respectively (Fig. 8B). This observation supports the hypothesis that KEAP1 interaction with $\mathrm{p} 62$ is favored in $\mathrm{Vps} 34^{\mathrm{cKO}}$, and that NRF2 is thus displaced and able to migrate to the nucleus to regulate gene expression.

We also evaluated macroautophagy/mitophagy by immunolocalizing TOM20 and LAMP-1. In Vps $34^{\text {cKO }}$ thyrocytes, TOM20-labeled structures did not colocalize with the more abundant, enlarged LAMP-1+ structures (Supplementary Fig. S3A), as we also reported in Vps34 ${ }^{\mathrm{cKO}}$ kidney proximal tubular cells (19). This suggested that sequestration of mitochondria into autophagosomes is either not triggered, which is unlikely for altered cells, or abortive at $\mathrm{P} 14$ in $\mathrm{Vps} 34^{\mathrm{cKO}}$ thyrocytes, and/or that fusion of autophagosomes with lysosomes is prevented. We then evaluated the chaperone-mediated autophagy by immunolocalizing LAMP-2A. As compared with control thyroid, LAMP-2A-labeled structures were more abundant in $\mathrm{Vps} 34^{\text {cKO }}$ thyrocytes (Supplementary Fig. S3B), as we also reported in $\mathrm{Vps} 34^{\mathrm{cKO}}$ kidney proximal tubular cells (19).

\section{Luminal cells present in Vps34 ${ }^{c K O}$ follicles are macrophages}

Finally, we investigated the origin of the cells present in the colloidal space. As shown by Figure 7A, cells trapped in the follicular lumen showed a strong LAMP-1 signal (Fig. 7A). However, they were negative for E-cadherin (Figs. 1D and $5 \mathrm{~A})$. In addition, we found that luminal cells were also negative for the permanently expressed thyrocyte-restricted transcription factor TTF-1 (NKX2.1) (Fig. 9A), indicating that these cells were not derived from the thyrocyte lineage. Lineage-tracing experiments on Pax8-Cre; Vps34 $4^{f / f}$; ROSA$S T O P-Y F P$ pups at $\mathrm{P} 14$ further revealed YFP-positive signal only in follicle-delineating thyrocytes and not in the luminal cells (Fig. 9B). Thus, luminal cells had never expressed Pax8 and are therefore not derived from thyrocyte progenitors. Although infiltration by $\mathrm{C}$-cells is a possibility, we failed to label luminal cells for the Prox 1 transcription factor. As 
A

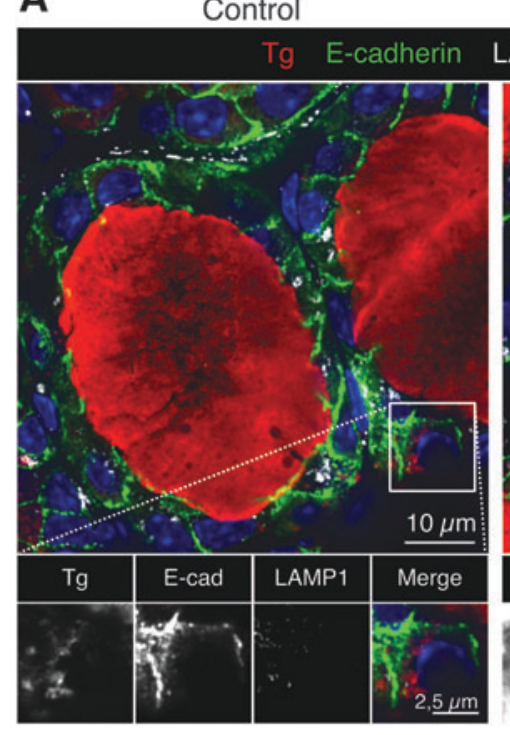

B

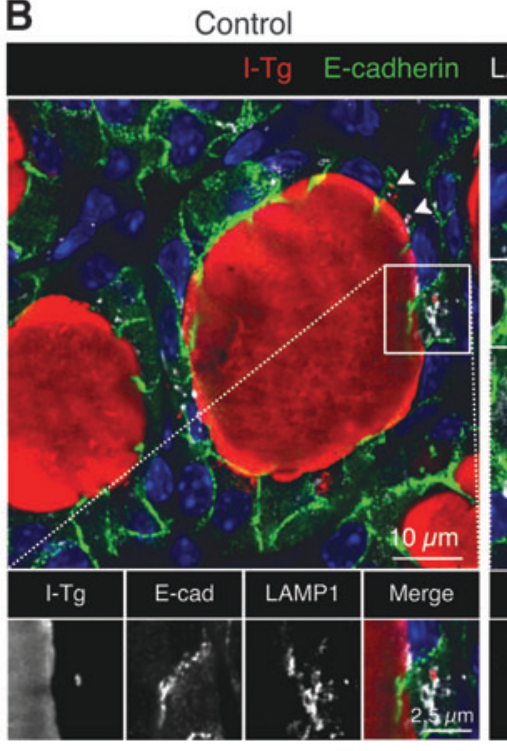

Vps34 $4^{\text {cKo }}$

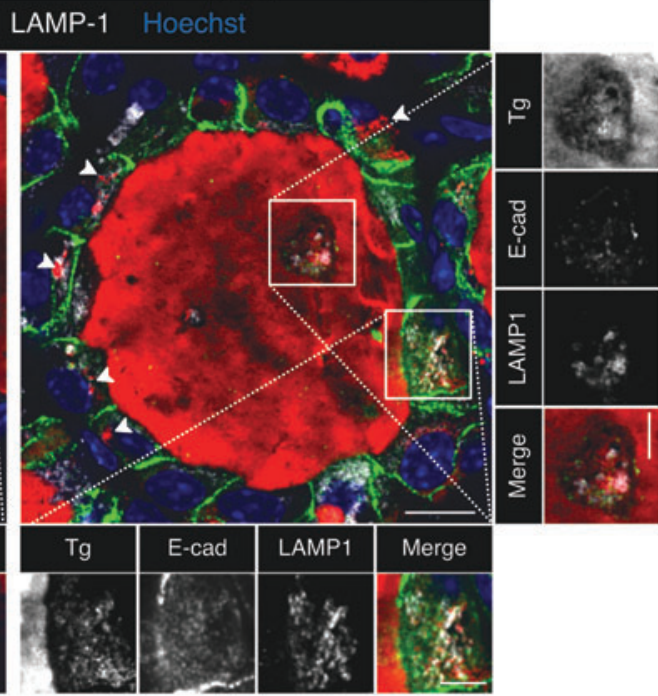

Vps34 ${ }^{\text {cKO }}$

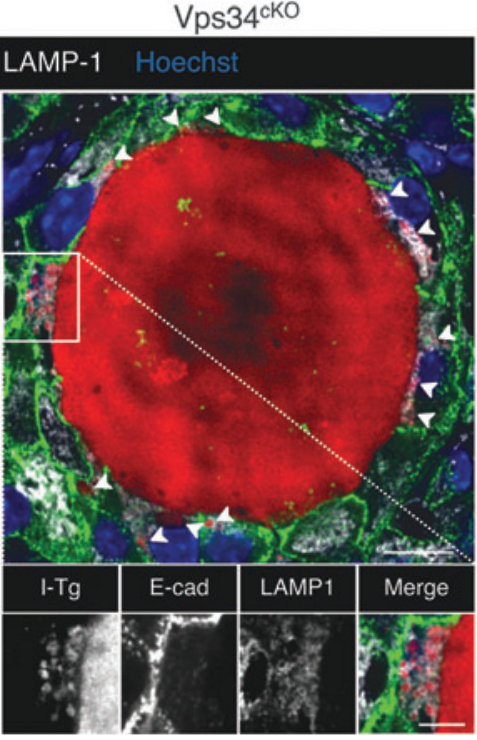

FIG. 7. $\quad \mathrm{Vps} 34^{\mathrm{cKO}}$ thyrocytes display increased LAMP-1 signal and impaired I-Tg proteolytic processing. (A) Thyroid sections from control (left) and $\mathrm{Vps} 34^{\mathrm{cKO}}$ (right) labeled for Tg (red), E-cadherin (green), and lysosomal LAMP-1 (white). Nuclei are labeled by Hoechst (shown in blue). In control, thyrocytes rarely contain intracellular Tg and LAMP-1 signal is weak. In $\mathrm{Vps} 34^{\mathrm{cKO}}$, most thyrocytes have intracellular $\mathrm{Tg}$ (arrowheads) and LAMP-1 signal is much increased. Insets show magnification with separate emissions, then merged, channels. Note colocalization of $\mathrm{Tg}$ with LAMP-1 in luminal cells (at right). (B) Thyroid sections from control (left) and $\mathrm{Vps} 34^{\mathrm{cKO}}$ (right) labeled for I-Tg (red), E-cadherin (green), and lysosomal LAMP-1 (white). Nuclei are labeled by Hoechst (shown in blue). As compared with control follicles which show a weak signal for LAMP-1, and rare intracellular I-Tg, LAMP-1 signal is intense in Vps $34^{\text {cKO }}$ thyrocytes and intracellular I-Tg dots are frequently observed (arrowheads). As shown in the enlargements below, LAMP-1-labeled structures in $\mathrm{Vps} 34^{\mathrm{cKO}}$ thyrocytes are enlarged or vacuolated as compared with control. luminal cells displayed LAMP-1 signal and were also positive for Tg (Fig. 7A), we tested the possibility that luminal cells were infiltrating macrophages. This is indeed the case because luminal cells were positive for the macrophage marker F4/80 (Fig. 10A), but not by E-cadherin. To confirm that colloid was consumed by infiltrated macrophages, we performed a triple immunolabeling for F4/80, LAMP-1, and I-Tg. Luminal F4/ 80-positive cells displayed huge LAMP-1-positive lysosomes filled with I-Tg (Fig. 10B). Thus, colloid consumption ( Tg in Fig. 7A and I-Tg in Fig. 9D) by infiltrated macrophages provides a third potential explanation for the low T4 plasma level observed in $\mathrm{Vps} 34^{\mathrm{cKO}}$.

\section{Discussion}

In this study, we report that deleting Vps34 in thyrocytes by Pax8-Cre-driven recombination causes several defects in the thyroid: (i) doubling of thyroid weight and perturbed thyroid parenchyma organization, with reduced $\mathrm{PAS}^{+}$colloidal spaces; (ii) severe hypothyroidism with collapsed plasma T4 levels and very high TSH; (iii) a strong decrease of ${ }^{125} \mathrm{I}$ organification, at comparable ${ }^{125}$ I uptake, and of T4 formation on Tg [detected by immunofluorescence as early as postnatal day 3 (P3)]; (iv) defective apical polarization; (v) impaired lysosomal proteolysis; and (vi) infiltration of macrophages in the colloid. Some of these features, combined with delayed "eye opening" and impaired postnatal growth after 2 weeks (18), phenocopy the impact of the Duoxa2 KO in the thyroid (34).

DUOXA2 is a chaperone protein required for the correct localization of DUOX2 at the apical pole of thyrocytes, where the complex (DUOX2/DUOXA2) produces $\mathrm{H}_{2} \mathrm{O}_{2}$. In the absence of DUOXA2, $\mathrm{H}_{2} \mathrm{O}_{2}$ is not produced, and subsequent TPO-mediated oxidation of iodide into reactive compounds and $\mathrm{Tg}$ iodination are abolished (34). The similarity of the severity of hypothyroidism in $\mathrm{Vps} 34^{\mathrm{cKO}}$ and Duoxa 2 KO mice prompted us to have a closer look at DUOXA2 in $\mathrm{Vps} 34^{\mathrm{cKO}}$. We found that the expression of Duoxa2 started decreasing after P3, reaching twofold lower values at P14. It is interesting to note that expression of Duox2 and Duoxa2 mRNAs was quantitatively different, despite the fact that they 

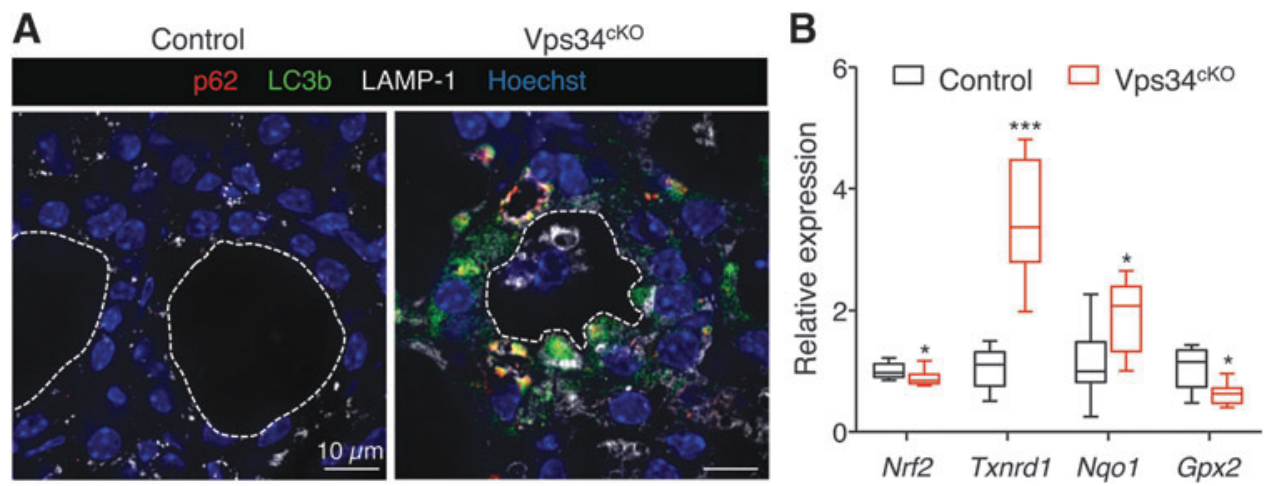

FIG. 8. Vps34 ${ }^{\mathrm{cKO}}$ thyrocytes show strong accumulation of p62 and LC3b dots. (A) Thyroid sections from control (left) and $\mathrm{Vps} 34^{\mathrm{cKO}}$ (right) labeled for p62 (red), LC3b (green), and lysosomal LAMP-1 (white). Nuclei are labeled by Hoechst (shown in blue). Compared with control follicles, which show low LAMP-1 and almost no signal for p62 and $\mathrm{LC} 3 \mathrm{~b}$, all three markers are very strong in Vps34 ${ }^{\mathrm{CKO}}$ thyroid sections. p62 perfectly colocalizes with LC3b and labels large aggregates. These aggregates are adjacent to LAMP-1-positive structures. (B) Increased NRF2 signaling. Gene expression analysis by RT-qPCR, presented as boxes with median and percentiles. As compared with control thyroid (black boxes), expression of Nrf2 is reduced in $\mathrm{Vps} 34^{\mathrm{cKO}}$ (red boxes), but level of two of three NRF2 target genes, Txnrd1 and Nqo1, is increased. Boxes with median and percentiles of $\sim 9$ control and $9 \mathrm{Vps} 34^{\mathrm{cKO}}$ samples; $* p<0.05$ and $* * * p<0.001$ by MannWhitney nonparametric test.

share the same promoter (35). Whether decreased Duoxa2 mRNA expression is reflected by an equivalent twofold decrease of DUOX2/DUOXA2 complex at the apical pole is unknown. However, it is very unlikely that a twofold decrease would by itself impact $\mathrm{Tg}$ iodination to such a severe extent, since heterozygous mice for Duoxa2 deletion have virtually no phenotype. In addition, our measurements of $\mathrm{H}_{2} \mathrm{O}_{2}$ levels in total $\mathrm{Vps} 34^{\mathrm{cKO}}$ thyroid extracts support normal, or increased, function of the DUOX2/DUOXA2 complex.

Instead, based on the known functions of Vps34 in kidney proximal tubular cells, where its inactivation causes lack of apical localization of endocytic receptors (megalin, cubilin) and solute transporters (NaPi-IIa, SGLT-2) (19), it would be extremely interesting to localize actors of thyroid hormonogenesis on thyroid sections, and assess their basolateral or apical addressing in $\mathrm{Vps} 34^{\mathrm{cKO}}$ thyrocytes. Unfortunately, reliable antibodies to detect most of these proteins are not yet available for mice. Nevertheless, ${ }^{125}$ I uptake and processing experiments suggest normal localization and function of the NIS, and/or the putative alternative transporter SLC26A7 (3), and rather support the hypothesis of defective apical localization of one or several actors involved in thyroid hormonogenesis (Ano1, pendrin (SLC26A4), TPO, DUOX, DUOXA).

Characteristic histopathological alterations combined with the very high plasma TSH levels and a twofold increase in $T$ shr expression in Vps $34^{\mathrm{cKO}}$ thyroid could suggest that thyrocytes are in a hyperstimulated state. For example, DuoxA2 KO mice, which display very high TSH levels, present a 20- and 5-fold higher expression level of Nis and Tpo, as compared with controls (34). However, the expression of these two sensitive target genes of the TSH signaling pathway, Nis and $T p o$, was surprisingly unchanged in $\mathrm{Vps} 34^{\mathrm{cKO}}$ mice, thus arguing against thyrocyte hyperstimulation.

We favor instead the hypothesis of TSHR mistrafficking into intracellular vesicles. Recent work in Drosophila revealed that Vps34 inactivation or pharmacological inhibition using the small molecule inhibitor SAR405 causes alteration of cell polarity and disruption of epithelial architecture by relieving LKB1 inhibition and triggering JNK activation
(14). A role of Vps34 in epithelial organization and polarity was also observed in 3D cultures of Caco-2 kidney cells (14). It would be interesting to analyze the activation states of LKB 1 and $\mathrm{JNK}$ in $\mathrm{Vps} 34^{\mathrm{cKO}}$ thyroid tissue, and, if modified, to cross $\mathrm{Vps} 34^{\mathrm{cKO}}$ with floxed LKB1 alleles.

The expression patterns of the two SLC transporters, $S l c 26 a 7$ and Slc26a4, in $\mathrm{Vps} 34^{\mathrm{cKO}}$ mice are surprising. The decreased expression of Slc26a7 (fourfold) in $\mathrm{Vps} 34^{\mathrm{cKO}}$ may affect entry of iodine in the thyroid. However, it should be mentioned that this alternative basolateral transporter, SLC26A7, may only play an indirect role in iodine uptake (3). In addition, expression of the main transporter, Nis, is 16-fold more important than that of Slc26a7. This may explain why ${ }^{125}$ I uptake is not affected. Expression of the apical Slc26a4 (pendrin) in $\mathrm{Vps} 34^{\mathrm{cKO}}$ was even more dramatic with a 20 -fold increase in expression. However, we do not favor the view that this would have affected apical transport of iodine. Indeed, in control thyroids, the expression levels of Slc26a4 were 60-fold lower than those of anocta$\min 1(6 \mathrm{Ct})$. This is compatible with a more prominent role for anoctamin1 in apical iodide transport (36).

These changes in expression of Slc26a7 and Slc26a4 could however impact thyrocyte ion balance. Indeed, SLC26A7 and SLC26A4 transporters have opposite actions on chloride ions at the basolateral and apical membranes, respectively. Decreased levels of SLC26A7 at the basolateral membrane may decrease the export of chloride out of the thyrocyte (3). On the contrary, increased levels of SLC26A4 at the apical membrane may increase the entry of chloride in the thyrocyte. Accumulation of chloride may in turn decrease intracellular $\mathrm{pH}$ and causes cellular stress in $\mathrm{Vps} 34^{\mathrm{cKO}}$.

The weak PAS staining in $\mathrm{Vps} 34^{\mathrm{cKO}}$ could be due to decreased exocytosis of $\mathrm{Tg}$ or increased $\mathrm{Tg}$ endocytosis. We frequently observed intracellular $\mathrm{Tg}$ in $\mathrm{Vps} 34^{\mathrm{cKO}}$ mice. We suggest that the defective process is the endocytic route rather than exocytosis because we readily observed intracellular structures positive for I-Tg. This is rarely the case in control thyrocytes where I-Tg is rapidly proteolytically processed. In 
A

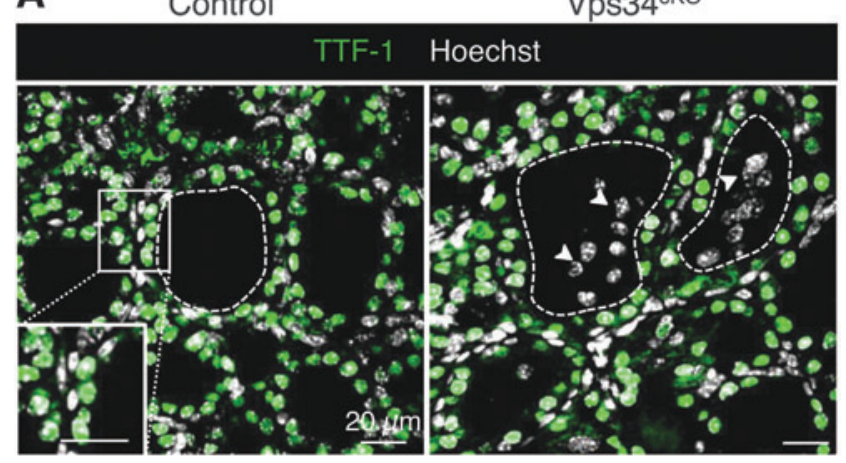

B

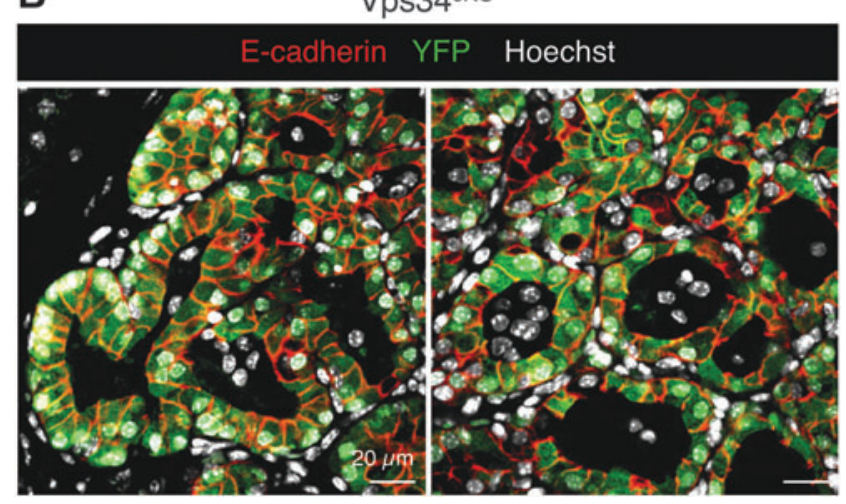

FIG. 9. Luminal cells in $\mathrm{Vps} 34^{\mathrm{cKO}}$ thyroid are not thyrocytes. (A) Immunolabeling for thyrocyte transcription factor1 (TTF-1, green); nuclei are visualized with the Hoechst stain (shown in white). In both control and $\mathrm{Vps} 34^{\mathrm{cKO}}$ thyroid, nuclei of thyrocytes circumscribing the follicular lumina are all labeled by the thyrocyte-specific transcription-factor-1, TTF-1. As indicated by the arrowheads, nuclei of luminal cells show no signal for TTF-1 (only white signal representing Hoechst). (B) Immunolabeling for E-cadherin (red) and YFP (green); nuclei are visualized with the Hoechst stain (shown in blue). Representative images of $\mathrm{Vps} 34^{\mathrm{cKO}}$ thyroid sections reveal expression of YFP only in cells surrounding the follicular lumina, that is, in cells where Pax8-Cre has been active. Luminal cells do not derive from thyrocyte progenitors as they are negative for YFP.

addition, our work demonstrates increased abundance and size of LAMP-1-positive late endosomes/lysosomes in $\mathrm{Vps} 34^{\mathrm{cKO}}$ thyrocytes, with accumulation of $\mathrm{Tg}$ and the autophagic marker p62, which is indicative of a defective lysosomal trafficking and/or function. In addition to impaired Tg iodination, low T4 plasma levels thus presumably result from impaired endocytic transport of $\mathrm{I}-\mathrm{Tg}$ to lysosomes and/or proteolytic excision of T3/T4 therein.

Several studies have indeed reported a role for Vps34 in endocytic trafficking to lysosomes $(13,15,30,37)$ and activation of lysosomal proteases (15). In our study on $\mathrm{Vps} 34^{\mathrm{cKO}}$ renal proximal tubular cells, we also observed an enlargement of lysosomes and their filling by undigested material, labeled for a variety of antigens (19). In Vps $34^{\mathrm{cKO}}$ thyrocytes, we also observed an increased abundance and size of LAMP-1-positive compartments filled with $\mathrm{Tg}$ and $\mathrm{I}-\mathrm{Tg}$. Based on these and previous findings showing that Vps34 deletion leads to late endosome/lysosome enlargement and defective lysosomal function (37), we assume a defective proteolytic excision of
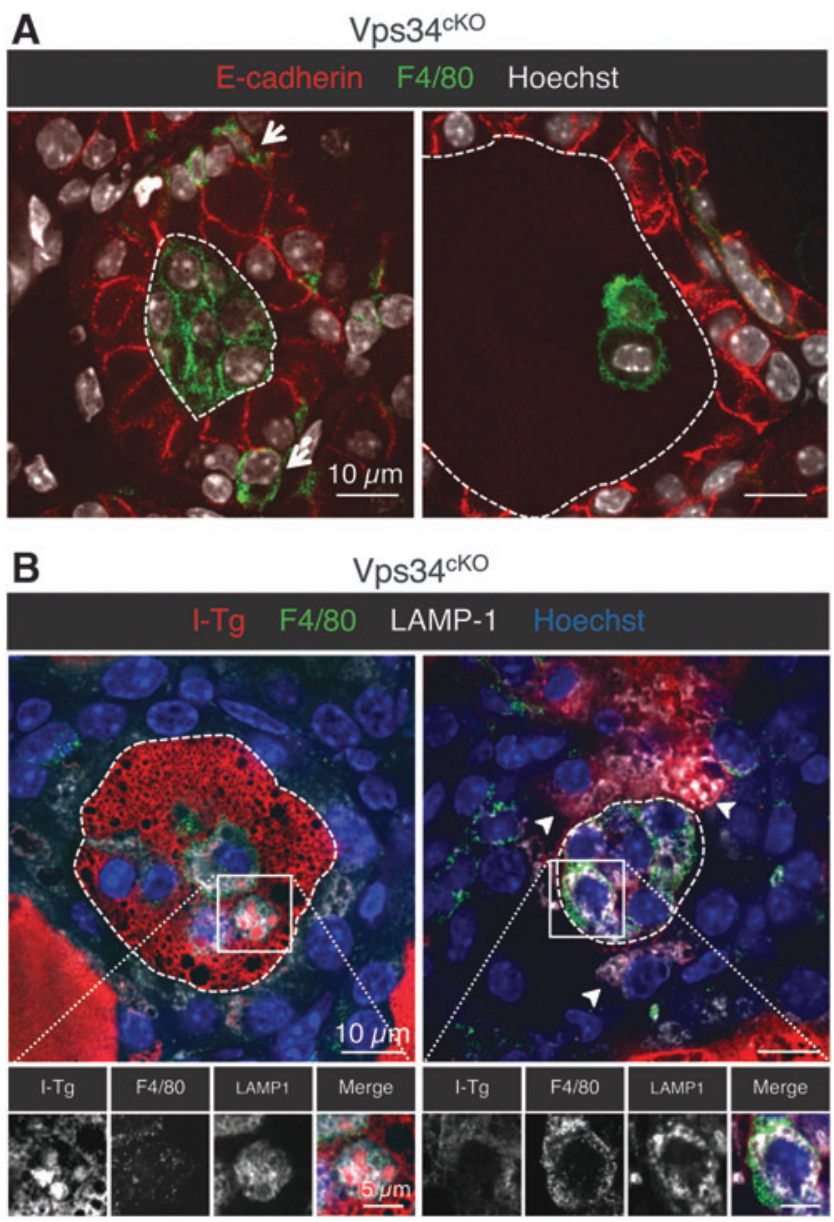

FIG. 10. Luminal cells in $\mathrm{Vps} 34^{\mathrm{cKO}}$ thyroid are macrophages. (A) Immunolabeling for E-cadherin (red), and for the conventional macrophage marker (F4/80, green); nuclei are visualized with the Hoechst stain (shown in white). In Vps34 ${ }^{\mathrm{cKO}}$ thyroid, F4/80 signal can be found in the interstitium (arrows), but also in the colloidal space, thus identifying luminal cells as infiltrating macrophages. (B) Luminal cells are taking up the colloid. Immunolabeling for I-Tg (red), F4/80 (green), and LAMP-1 (white). Nuclei are visualized with the Hoechst stain (shown in blue). Luminal cells in $\mathrm{Vps} 34^{\mathrm{cKO}}$ have abundant LAMP-1 structures that surround I-Tg droplets. Arrowheads show additional I-Tg in thyrocytes. Broken lines indicate luminal contours.

T3/T4 from I-Tg, analogous to what we reported in cystinotic $\mathrm{Ctns}^{-1-}$ mice (38).

Cystinosis is a lysosomal storage disease caused by deletion or inactivating mutations of the lysosomal cystine transporter cystinosin (39). Defective cystinosin impacts lysosomal proteolysis, presumably due to endolysosomal mislocalization, impaired procathepsin maturation, and altered luminal redox status; moreover, autophagic flux is altered (40). Like cystinotic patients, $\mathrm{Ctns}^{-/}$mice show compensated hypothyroidism with moderate increase of $\mathrm{TSH}$, thyrocyte hyperplasia, and proliferation, combined with progressive colloid depletion and evidence of increased endocytosis into colloid droplets. Iodo-Tg could be detected in $\mathrm{Ctns}^{-/}$but not wild-type thyrocyte lysosomes, under identical labeling conditions, further indicating defective proteolysis. 
It has recently become clear that Vps34 may act on lysosome positioning, which is crucial to autophagosome formation $(41,42)$. Similar to the kidney proximal tubular cell defect, we observed an increased p62 signal in Vps $34^{\mathrm{cKO}}$ thyroids at P14. Accumulation of $\mathrm{p} 62$ and LC $3 \mathrm{~b}$ in $\mathrm{Vps} 34^{\mathrm{cKO}}$ indicates a block in the autophagy process. In addition, p62 accumulation suggests activation of the antioxidant NRF2 pathway by competitive binding of p62 to KEAP1 $(33,43)$. We indeed observed increased expression of two NRF2 target genes, namely the quinone reductase, Nqol, and the thioredoxin reductase 1, Txnrd1. Considering the expected key role of Vps34 in macroautophagy, our data on mitophagy do not prove, but are compatible with the suggestion that this important homeostatic process is abrogated upon Vps34 deficiency.

A final observation deserving discussion is the occurrence of viable cells in the follicular lumens of $\mathrm{Vps} 34^{\mathrm{cKO}}$ thyroids. Our first hypothesis was that defective endocytic and autophagic routes to the lysosomes could impact thyrocyte homeostasis, thus causing cellular stress. Cellular stress, induced by defective autophagosome and lysosomal function, or by activation of stress kinase such as JNK, could explain shedding of thyrocytes into the colloidal space. However, luminal cells of $\mathrm{Vps} 34^{\text {cKO }}$ thyroids were negative for E-cadherin and the thyrocyte-specific transcription factor TTF-1 (NKX2.1). Furthermore, lineagetracing experiments demonstrated that these luminal cells had never expressed Pax8 and thus did not derive from thyrocytes.

A second hypothesis was that the cellular stress and loss of tissue homeostasis would recruit macrophages. Indeed, we found that luminal cells were labeled for the conventional macrophage marker F4/80, are proliferating and display a high LAMP-1 signal. In addition, $\mathrm{Tg}$ and I-Tg colocalized with these macrophage lysosomes, demonstrating active endocytosis of the colloid "from within." This observation contributes to explaining the colloid exhaustion observed in $\mathrm{Vps} 34^{\mathrm{cKO}}$ mice and could thus be responsible for the low levels of circulating T4. Although the signal(s) attracting macrophages to the colloid is(are) unknown, the loss of tight junction integrity might facilitate their invasion.

\section{Author Contributions}

G.G. and T.S.W. performed the initial morphological and molecular studies and analyzed the data. O.D. and C.S. performed all the other experiments and prepared the figures for the revision. V.J. and A.S. participated in data collection and analysis. H.P.G.C. was involved in supervision of G.G. B.B. and B.V. provided the Vps34 mice, X.H.L. and S.R. assayed T4 and TSH levels, and C.M. provided expertise with 125I experiments. P.J.C. and C.E.P. conceived, designed, and supervised the project, and wrote the article. All authors have approved the final version of the article.

\section{Acknowledgments}

The authors thank Prof. C. Ris-Stalpers for iodothyroglobulin antibody, and Abdelkadder El Kaddouri and Claude Massart for technical help.

\section{Author Disclosure Statement}

B.V. is a consultant for Karus Therapeutics (Oxford, UK), iOnctura (Geneva, Switzerland), and Venthera (Palo Alto, CA) and has received speaker fees from Gilead. The other authors have no competing financial interest.

\section{Funding Information}

This work was supported by grants from the Fonds pour la Recherche Scientifique (F.R.S-FNRS, No. J.0076.18, Belgium), Université catholique de Louvain (Actions de Recherche concertées to CEP, ARC 15/20-065), and Fondation Roi Baudouin. S.R. and X.H.L. were supported by a grant DK15070 from the National Institutes of Health. Work in the laboratory of BV was supported by grants from the MRC (G0700755) and BBSRC (BB/I007806/1 and BB/M013278/1). The core facility for Imaging Cells and Tissues was also financed by National Lottery, Région bruxelloise, Région wallonne, Université catholique de Louvain, and de Duve Institute. G.G. held a fellowship from the Fonds pour la formation à la Recherche dans l'Industrie et l'Agriculture (FRIA, Belgium), T.W. was postdoctoral researcher supported by UCLouvain, O.D. is supported by Télévie, V.J. by the Cystinosis Research Foundation, C.S. is a UCLouvain teaching assistant, H.P.G.C. was a postdoctoral researcher, P.J.C is active Emeritus at UCLouvain/de Duve Institute, and C.E.P. is a senior research associate at F.R.S-FNRS.

\section{Supplementary Material}

Supplementary Figure S1

Supplementary Figure S2

Supplementary Figure S3

Supplementary Table S1

Supplementary Table S2

\section{References}

1. Colin IM, Denef JF, Lengele B, Many MC, Gerard AC 2013 Recent insights into the cell biology of thyroid angiofollicular units. Endocr Rev 34:209-238.

2. Carvalho DP, Dupuy C 2017 Thyroid hormone biosynthesis and release. Mol Cell Endocrinol 458:6-15.

3. Cangul H, Liao X-H, Schoenmakers E, Kero J, Barone S, Srichomkwun P, Iwayama H, Serra EG, Saglam H, Eren E, Tarim O, Nicholas AK, Zvetkova I, Anderson CA, Karet Frankl FE, Boelaert K, Ojaniemi M, Jääskeläinen J, Patyra K, Löf C, Williams ED, UK10K Consortium, Soleimani M, Barrett T, Maher ER, Chatterjee VK, Refetoff S, Schoenmakers N 2018 Homozygous loss-of-function mutations in SLC26A7 cause goitrous congenital hypothyroidism. J Clin Ivest Insight 3:e99631.

4. Koumarianou P, Gomez-Lopez G, Santisteban P 2017 Pax8 controls thyroid follicular polarity through cadherin-16. J Cell Sci 130:219-231.

5. Shivas JM, Morrison HA, Bilder D, Skop AR 2010 Polarity and endocytosis: reciprocal regulation. Trends Cell Biol 20: 445-452.

6. Rodriguez-Boulan E, Macara IG 2014 Organization and execution of the epithelial polarity programme. Nat Rev Mol Cell Biol 15:225-242.

7. Morrison HA, Dionne H, Rusten TE, Brech A, Fisher WW, Pfeiffer BD, Celniker SE, Stenmark H, Bilder D 2008 Regulation of early endosomal entry by the Drosophila tumor suppressors Rabenosyn and Vps45. Mol Biol Cell 19:4167-4176.

8. Bilanges B, Posor Y, Vanhaesebroeck B 2019 PI3K isoforms in cell signaling and vesicle trafficking. Nat Rev Mol Cell Biol 20:515-534.

9. Lindmo K, Stenmark H 2006 Regulation of membrane traffic by phosphoinositide 3-kinases. J Cell Sci 119:605614. 
10. Juhasz G, Hill JH, Yan Y, Sass M, Baehrecke EH, Backer JM, Neufeld TP 2008 The class III PI(3)K Vps34 promotes autophagy and endocytosis but not TOR signaling in Drosophila. J Cell Biol 181:655-666.

11. Backer JM 2008 The regulation and function of Class III PI3Ks: novel roles for Vps34. Biochem J 410:1-17.

12. Jaber N, Zong WX 2013 Class III PI3K Vps34: essential roles in autophagy, endocytosis, and heart and liver function. Ann NY Acad Sci 1280:48-51.

13. Bechtel W, Helmstädter M, Balica J, Hartleben B, Kiefer B, Hrnjic F, Schell C, Kretz O, Liu S, Geist F, Kerjaschki D, Walz G, Huber TB 2013 Vps34 deficiency reveals the importance of endocytosis for podocyte homeostasis. J Am Soc Nephrol 24:727-743.

14. O'Farrell F, Lobert VH, Sneeggen M, Jain A, Katheder NS, Wenzel EM, Schultz SW, Tan KW, Brech A, Stenmark H, Rusten TE 2017 Class III phosphatidylinositol-3-OH kinase controls epithelial integrity through endosomal LKB1 regulation. Nat Cell Biol 19:1412-1423.

15. Ronan B, Flamand O, Vescovi L, Dureuil C, Durand L, Fassy F, Bachelot M-F, Lamberton A, Mathieu M, Bertrand T, Marquette J-P, El-Ahmad Y, Filoche-Romme B, Schio L, Garcia-Echeverria C, Goulaouic H, Pasquier B 2014 A highly potent and selective Vps34 inhibitor alters vesicle trafficking and autophagy. Nat Chem Biol 10: 1013-1019.

16. Nascimbeni AC, Codogno P, Morel E 2017 Phosphatidylinositol-3-phosphate in the regulation of autophagy membrane dynamics. FEBS J 284:1267-1278.

17. Dupont N, Nascimbeni AC, Morel E, Codogno P 2017 Molecular mechanisms of noncanonical autophagy. Intl Rev Cell Mol Biol 328:1-23.

18. Carpentier S, N'Kuli F, Grieco G, Van Der Smissen P, Janssens V, Emonard H, Bilanges B, Vanhaesebroeck B, Gaide Chevronnay HP, Pierreux CE, Tyteca D, Courtoy PJ 2013 ClassIII phosphoinositide 3-kinase/VPS34 and dynamin are critical for apical endocytic recycling. Traffic 14: 933-948.

19. Grieco G, Janssens V, Gaide Chevronnay HP, N'Kuli F, Van Der Smissen P, Wang TS, Shan J, Vainio S, Bilanges B, Jouret F, Vanhaesebroeck B, Pierreux CE, Courtoy PJ 2018 Suppression of Vps34 PI 3-kinase activity in kidney proximal tubules abrogates apical trafficking and causes a Fanconi syndrome. Sci Rep 8: 14133.

20. Shan J, Jokela T, Skovorodkin I, Vainio S 2010 Mapping of the fate of cell lineages generated from cells that express the Wnt4 gene by time-lapse during kidney development. Differentiation 79:57-64.

21. Bouchard M, Souabni A, Busslinger M 2004 Tissuespecific expression of cre recombinase from the Pax8 locus. Genesis 38:105-109.

22. Valet C, Levade M, Chicanne G, Bilanges B, Cabou C, Viaud J, Gratacap MP, Gaits-Iacovoni F, Vanhaesebroeck B, Payrastre B, Severin S 2017 A dual role for the class III $\mathrm{PI} 3 \mathrm{~K}, \mathrm{Vps} 34$, in platelet production and thrombus growth. Blood 130:2032-2042.

23. Pohlenz J, Maqueem A, Cua K, Weiss RE, Van Sande J, Refetoff S 1999 Improved radioimmunoassay for measurement of mouse thyrotropin in serum: strain differences in thyrotropin concentration and thyrotroph sensitivity to thyroid hormone. Thyroid 9:1265-1271.

24. Delmarcelle AS, Villacorte M, Hick AC, Pierreux CE 2014 An ex vivo culture system to study thyroid development. J Vis Exp 6:88.
25. Hick AC, Delmarcelle AS, Bouquet M, Klotz S, Copetti T, Forez C, Van Der Smissen P, Sonveaux P, Collet JF, Feron O, Courtoy PJ, Pierreux CE 2013 Reciprocal epithelial: endothelial paracrine interactions during thyroid development govern follicular organization and C-cells differentiation. Dev Biol 381:227-240.

26. Dupasquier S, Delmarcelle AS, Marbaix E, Cosyns JP, Courtoy PJ, Pierreux CE 2014 Validation of housekeeping gene and impact on normalized gene expression in clear cell renal cell carcinoma: critical reassessment of YBX3/ ZONAB/CSDA expression. BMC Mol Biol 15:9.

27. Massart C, Hoste C, Virion A, Ruf J, Dumont JE, Van Sande J 2011 Cell biology of $\mathrm{H}_{2} \mathrm{O}_{2}$ generation in the thyroid: investigation of the control of dual oxidases (DUOX) activity in intact ex vivo thyroid tissue and cell lines. Mol Cell Endocrinol 343:32-44.

28. Zhou X, Takatoh J, Wang F 2011 The mammalian class 3 PI3K (PIK3C3) is required for early embryogenesis and cell proliferation. PLoS One 6:e16358.

29. Chen J, Chen MX, Fogo AB, Harris RC, Chen JK 2013 $\mathrm{mVps} 34$ deletion in podocytes causes glomerulosclerosis by disrupting intracellular vesicle trafficking. J Am Soc Nephrol 24:198-207.

30. Bechtel, W, Helmstädter M, Balica J, Hartleben B, Schell C, Huber TB 2013 The class III phosphatidylinositol 3-kinase PIK3C3/VPS34 regulates endocytosis and autophagosomeautolysosome formation in podocytes. Autophagy 9:10971099.

31. Cohen-Kaplan V, Ciechanover A, Livneh I 2016 p62 at the crossroad of the ubiquitin-proteasome system and autophagy. Oncotarget 7:83833-83834.

32. Bjorkoy G, Lamark T, Pankiv S, Overvatn A, Brech A, Johansen T 2009 Monitoring autophagic degradation of p62/SQSTM1. Methods Enzymol 452:181-197.

33. Ziros PG, Habeso IG, Chartoumpekis DV, Ntalampyra E, Somm E, Renaud CO, Bongiovanni M, Trougakos IP, Yamamoto M, Kensler TW, Santisteban P, Carrascao N, Ris-Stalpers C, Amendola E, Liao XH, Rossich L, Thomasz L, Juvenal GJ, Refetoff S, Sykiotos GP 2018 NFE2-related transcription factor 2 coordinates antioxidant defense with thyroglobulin production and iodination in the thyroid gland. Thyroid 28:780-798.

34. Grasberger H, De Deken X, Mayo OB, Raad H, Weiss M, Liao XH, Refetoff S 2012 Mice deficient in dual oxidase maturation factors are severely hypothyroid. Mol Endocrinol 26:481-492.

35. Christophe-Hobertus C, Christophe D 2010 Delimitation and functional characterization of the bidirectional THOXDUOXA promoter regions in thyrocytes. Mol Cell Endocrinol 317:161-167.

36. Twyffels L, Strickaert A, Virreira M, Massart C, Van Sande $\mathrm{J}$, Wauquier C, Beauwens R, Dumont JE, Galietta LJ, Boom A, Kruys V 2014 Anoctamin-1/TMEME16A is the major apical iodide channel of the thyrocyte. Am J Physiol Cell Physiol 307:1102-1112.

37. Jaber N, Mohd-Naim N, Wang Z, DeLeon JL, Kim S, Zhong H, Sheshadri N, Dou Z, Edinger AL, Du G, Braga VM, Zong WX 2016 Vps34 regulates Rab7 and late endocytic trafficking through recruitment of the GTPaseactivating protein Armus. J Cell Sci 129:4424-4435.

38. Gaide Chevronnay HP, Janssens V, Van Der Smissen P, Liao XH, Abid Y, Nevo N, Antignac C, Refetoff S, Cherqui S, Pierreux CE, Courtoy PJ 2015 A mouse model suggests two mechanisms for thyroid alterations in infantile cysti- 
nosis: decreased thyroglobulin synthesis due to endoplasmic reticulum stress/unfolded protein response and impaired lysosomal processing. Endocrinology 156: 2349-2364.

39. Gahl WA, Thoene JG, Schneider JA 2002 Cystinosis. N Engl J Med 347:111-121.

40. Cherqui S, Courtoy PJ 2017 The renal Fanconi syndrome in cystinosis: pathogenic insights and therapeutic perspectives. Nat Rev Nephr 13:115-131.

41. Hong Z, Pedersen NM, Wang L, Torgersen ML, Stenmark H, Raiborg C 2017 PtdIns3P controls mTORC1 signaling through lysosomal positioning. J Cell Biol 216:4217-4233.

42. Korolchuk VI, Rubinsztein DC 2011 Regulation of autophagy by lysosomal positioning. Autophagy 7:927-928.

43. Komatsu M, Kurokawa H, Waguri S, Taguchi K, Kobayashi A, Ichimura Y, Sou YS, Ueno I, Sakamoto A, Tong
KI, Kim M, Nishito Y, Iemura S, Natsume T, Ueno T, Kominami E, Motohashi H, Tanaka K, Yamamoto M 2010 The selective autophagy substrate p62 activates the stress responsive transcription factor $\mathrm{Nrf} 2$ through inactivation of Keap1. Nat Cell Biol 12:213-223.

Address correspondence to: Christophe E. Pierreux, PhD Cell Biology Unit

de Duve Institute and Université Catholique de Louvain 75, Avenue Hippocrate Brussels B-1200 Belgium

E-mail: christophe.pierreux@uclouvain.be 